\title{
The purification of the environment from hydrogen sulphide by using wet electro-filter
}

\author{
Leonid Andreev ${ }^{1, *}$, Vladimir Yurkin ${ }^{1}$, and Yekaterina Basumatorova ${ }^{1}$ \\ ${ }^{1}$ Federal State Budgetary Educational Institution of Higher Education «Northern Trans-Ural State \\ Agricultural Universtity», Tyumen, Russia
}

\begin{abstract}
As a result of industrialization modern agro-industrial production and development of the industrial base, animal production meets with some problems. Without solving this problem, further, development becomes difficult. One such problem related to increasing a specific density of planting animals on limited. As a result, this problem leads to worsening sanitation and hygiene on the territory of animal stock and outside. One of the most hazardous and dangerous gas components is hydrogen sulfide. This component generates in animal premises. The hydrogen sulfide is very dangerous for animals, peoples and technological equipment. One from modern solutions is the wet electro filter filtration technology with wet one zoned filter. The technology combines the high efficiency of purification, high technology, and automatization. The theoretical process models and lab research showed the high efficiency of environment purification from hydrogen sulphide. Using the technology supplies a level of hydrogen sulphide in the environment of animal premises in acceptable limits. These lead to increase in production figures and agro-industry culture.
\end{abstract}

\section{Introduction}

The analysis of modern industrial methods of the animal industry showed to the strong tendency of increasing specific density of animals on the limited territory in animal premises, due to animal premises is allocating a significant number of varied hazards. This hazard is aerosol(dust) parts, microorganisms, hazardous gases (hydrogen sulfide, diarrheal gases, etc.). The concentration of hazards significantly higher than acceptable limits $[1,2$, $3,4]$.

Decreasing of level hazards in animal premises environment to recommend limits is carry out the mechanical supply and exhaust ventilation. In doing so in air pollution continuously is releasing a significant number of various hazards and thermal energy, this relates to a long cold-weather period. This leads to a decrease in the energy efficiency of agro-industry. Also, this leads to an increase in the risk of interchange between animal premises corpses, decreasing working conditions and increasing environment load.

One from perspective solution these problems is to use systems of partial recirculation of air ventilation with high efficiency and purification, which is recycled 84-85 percent of

*Corresponding author: andreev@tmn-tlt.ru 
air ventilation back in premises after purification and cleaning with release 15-16 percent in atmosphere. The purpose of the release is to deleting carbon dioxide and replace him with clean air. $[5,6]$.

In $[7,8]$ we have reviewed a task about cleaning and purification recycling air of animal premises. This task recommended using an air filter with 90 percent efficiency of cleaning the air. This filter has an opportunity to realization the continuously regeneration of filter elements.

\section{Materials and methods}

In the modern industry develops high quantity the filters and filters elements $[9,10]$. The filter's main indicators are efficiency, unit air load, resist and capacity of dust. Analysis and comparative assessment of these indicators revealed a clear advantage of electrostatic precipitators. This advantage is a low aerodynamic resist, high-stepped purification, ability to catch parts sizes: $10 \ldots 0,01 \mu \mathrm{m}$ and lower, ability to regeneration filters elements, automation capabilities for all cleaning processes, low energy, and low cost. [11, 12].

The filters by-products are ozone and atom oxygen, which as a strong oxidizer to effective clean air from hazardous and smell gases. [13, 14].

However, these electro filters have a high cost and need high-quality personal for exploitation and using in agro-industry. The air electrostatic filters designed and manufactured in our country, designed for air supply systems with air in various technological processes, cement industry, non-ferrous metallurgy, industry, energy enterprises, etc. These filters cannot respond to all zoo-technic requirements, which are being put in these installations.

As it is still intact have been developed are special wet one-zoned filter (WOF) (pic.1), intended for high-effective cleaning and purification recycling air of animal premises. [16, 17].

The WOF consists of two parts: a high part with corona discharge electrodes and a high voltage insulators system; a lower part with a reservoir for liquid and system of delete of unpurified liquid through the drain valve. As corona discharge electrodes use to needle or wire electrodes. Precipitation electrodes are implemented in the form of parallel plane discs rotating by electro filter's shaft [17].

Precipitation electrodes, rotating with a certain speed in the shaft of electro filter, constantly are mixing by a liquid in the lower part of the electro filter. Precipitation of aerosol parts from the air stream happens in the high part of the electro filter, covered by a thin layer of a liquid surface of precipitation electrodes. 

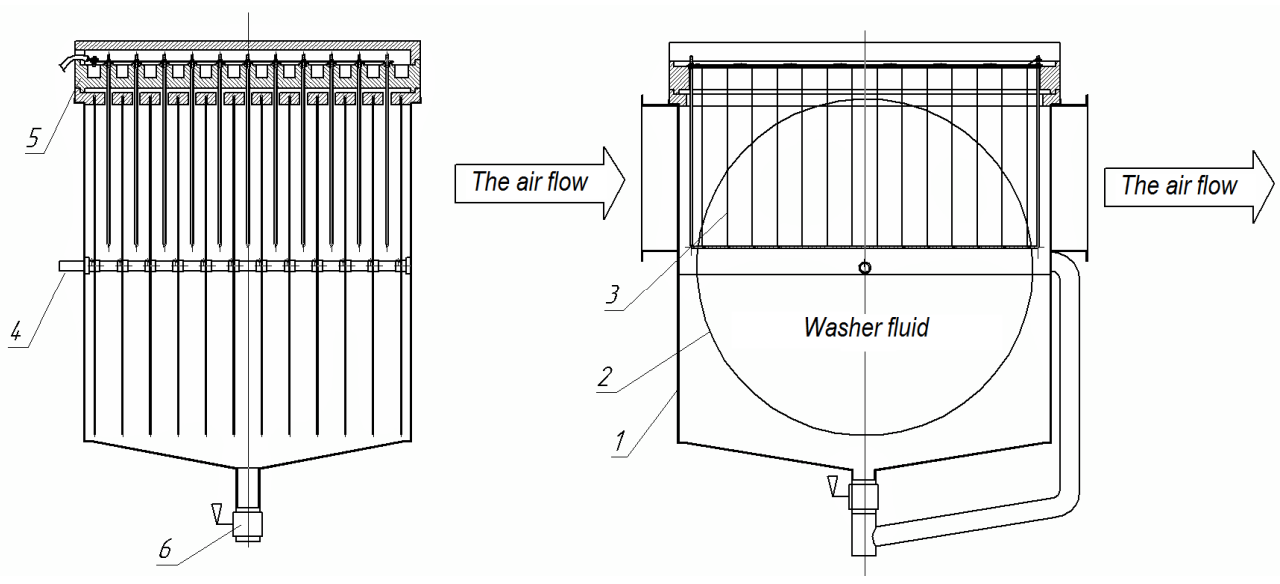

a)

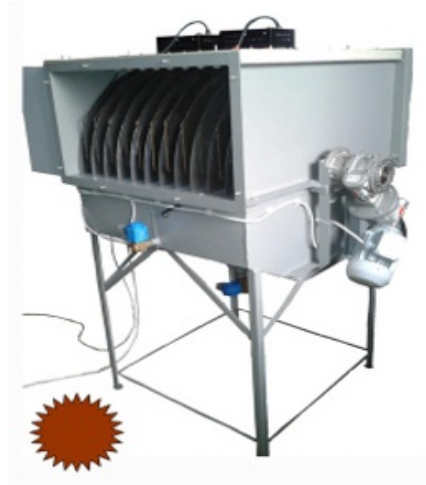

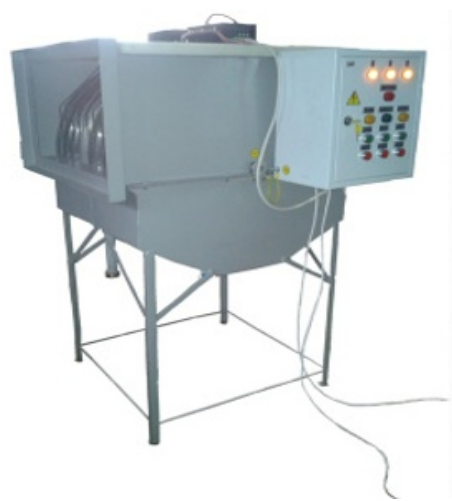

b)

Fig. 1.The wet one-zoned filter: a) device; б) appearance. 1 - Corps; 2 - Electrodes; 3 - Corona discharge electrodes; 4 - Electro filter shaft; 5 -insulation board; 6 - flush valve.

The construction of this electro filter allows us to constantly clean precipitation electrodes from condensed aerosol and to clean up a filtering air from hazardous gaseous components. This way of clean by ozone and absorb liquid covers precipitation electrodes.

The efficiency of the environment's cleaning of animal premises with aid by WOF from dust and aerosol parts can determine by the Deitch's equation [18]:

$$
\eta=1-\exp \left(-\frac{w l}{h u}\right)
$$

Where $\mathrm{w}$ - speed rate of parts, $\mathrm{m} / \mathrm{s} ; \mathrm{h}$-distance between electrodes, $\mathrm{m} ; \mathrm{u}$ - the speed of air stream, $\mathrm{m} / \mathrm{s} ; 1$ - active length of electro filter, $\mathrm{m}$

In [19] considered tasks of identifying the efficiency of air cleaning WOF from microorganisms. A target page is based on the graphical dependency quantity of colonyforming parts (CFP) in the researched air capacity from aerosol parts concentration in current capacity [9]. (Fig. 2). 


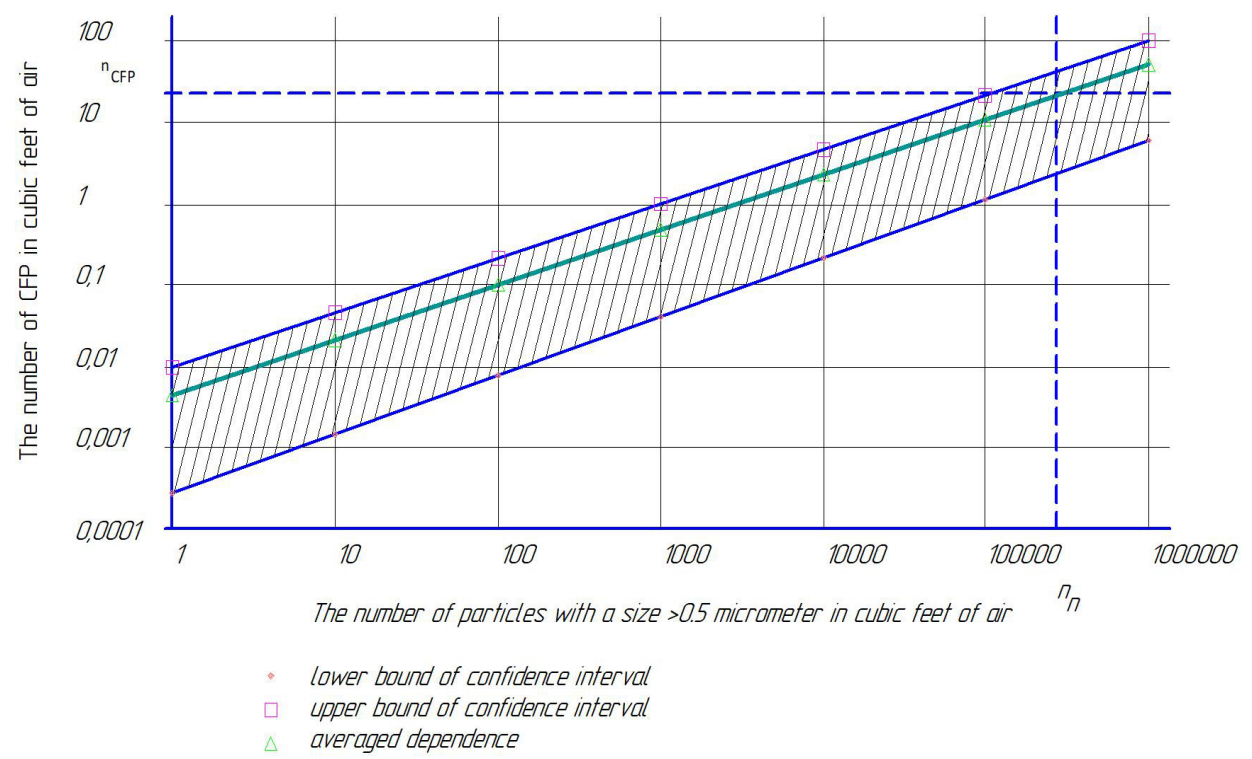

Fig.2 Graphical dependency quantity of colony-forming parts (CFP)

The dependency of CFP quantity in the environment from a quantity parts size higher than $0.5 \mu \mathrm{m}$ and more.

Received in [19] analytical expression allows to identify the air cleaning efficiency WOF from microorganisms $\eta \mathrm{KOE}$ by value air cleaning efficiency $\eta \Pi$ this electro filter from aerosol parts than $0.5 \mu \mathrm{m}$ and more.

$$
\eta_{K O E}=1-\left(1-\eta_{n}\right)^{0,66}
$$

Decrease concentration of hazardous and smell gaseous in cleaning the air of an electro filter happens in result oxidation by ozone. Given that ozone in an electro, the filter is forming in a corona case, it can be assumed what the most intensifies oxidation reaction happening in an airstream immediately adjacent to corona electrodes. Decreasing of hazardous components in this regard be replenished in the resulting movement his from length between electrodes under the effect of air stream pulses. In the result of turbulent pulse action diffusion space between condensed and corona, electrodes establish a certain distribution concentration of hazardous and gaseous components. Let us suppose what law of components concentration for each electro filter inter-section is the same and not dependence from a length of electro filter entrance. The absolute value of hazardous components concertation has been decreased.

The air-cleaning efficiency, in this case, is determined by the average capacity concentration of components in an electro filter section $\mathrm{dx}$ (Picture 3 ) is designated Cix, $\mathrm{mg} / \mathrm{m} 3$.

Then a mass of hazardous gaze in value interelectrode space a length $\mathrm{dx}$, located at a distance $1 \mathrm{x}$ from the entrance (Picture 3 ) is:

$$
m_{B}=C_{i x} \cdot 2 b h d x
$$

Decrease of hazardous gaseous components mass for a time $d t$ in value $2 b h d x$ Is: 


$$
d m_{B}=-C_{i x} k_{i} \cdot 2 b h d x d t
$$

Where ki - constant speed of dissolution (oxidation) i-st hazardous gaseous component $\frac{1}{c}[20,21]$. Mixed (3) and (4) as result is:

$$
\begin{aligned}
& \frac{d m_{B}}{m_{B}}=-k_{i} d t \\
& \frac{d C_{i x}}{C_{i x}}=-k_{i} d t
\end{aligned}
$$

In the result of integrating (6) is a dependency between the average substance of i-st hazardous gaseous component on entrance and exit of the electro filter:

$$
C_{i 2}=C_{i 1} \cdot \exp \left(-k_{i} \cdot t\right)
$$

Where Ci1 - concentration of i-st hazardous gaseous component on the entrance of electro filter

$\mathrm{Ci} 2$ - concentration of i-st hazardous gaseous component on the exit electro filter

Applying in (7) $t=\frac{l}{u}$, where $\mathrm{u}-$ speed of air stream, considering what $\eta=1-\frac{C_{i 2}}{C_{i 1}}$ as result is:

$$
\eta=1-\exp \left(-\frac{k_{i} l}{u}\right)
$$

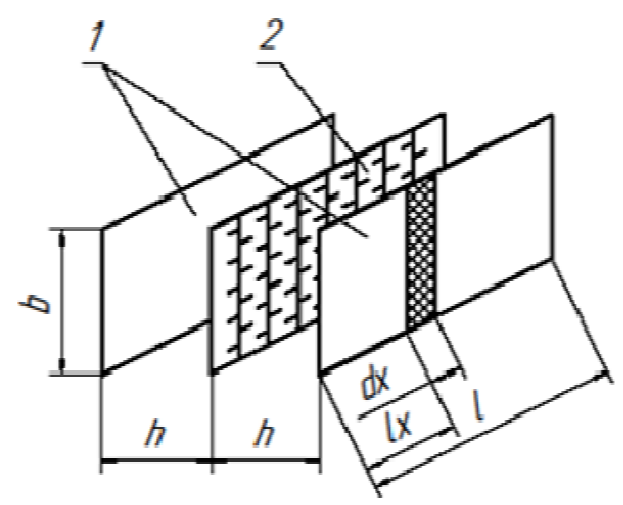

Fig. 3. One zoned electro filter: 1- condensed electrodes; 2- corona electrodes. 
From (8) show, what is an air-cleaning efficiency in the one zoned electro - filter from i-st hazardous gaseous component to increase with an increasing constant speed of oxidation ki and active length of electro filter 1 and decrease with increasing from a speed of air stream $u$.

When air gets through the wet one zoned electro filter. In his alongside oxidation hazardous gaseous component by ozone, for some from (for example $\mathrm{NH}_{3}$ ) is possibly absorption by liquid (for example $\mathrm{H}_{2} \mathrm{O}$ ), moistening in condensed electrodes. For the process intensification of absorption, a moistening mixture may be enriched by special chemical components. In this case decrease of i-st hazardous gaseous component mass in the electro filter due to oxidation by ozone and absorption, moistening condensed electrodes by liquid for time dt would be:

$$
d m_{\Sigma}=\left(d m+d m^{\prime}\right)
$$

Where $-\mathrm{dm}$ - decrease of gaze mass by oxidation by ozone from equation (4).

$\mathrm{dm}$ ' - decrease of gaze mass by liquid absorption on a plane condensed electrode

For dm' can write equation:

$$
d m^{\prime}=-C_{i x} k_{i}^{\prime} \cdot 2 b d x d t,
$$

Where $k^{\prime} i$ - constant speed of absorption of i-st hazardous gaseous component by liquid, moistening by condensed electrodes.

Applying (4) and (10) in (9) as result is:

$$
d m_{\Sigma}=-C_{i x} 2 b h d x\left(k_{i}+k_{i}^{\prime}\right) d t .
$$

Combining (3) and (11), we obtain:

$$
\begin{gathered}
\frac{d m_{\Sigma}}{m_{\Sigma}}=-\left(k_{i}+k_{i}^{\prime}\right) d t \text { или } \\
\frac{d C_{i x}}{C_{i x}}=-\left(k_{i}+k_{i}^{\prime}\right) d t .
\end{gathered}
$$

After integrating (13) receive is a ratio between average of i-st hazardous gaseous component on entrance and exit of the wet electro filter

$$
C_{i 2}=C_{i 1} \cdot \exp \left[-\left(k_{i}+k_{i}^{\prime}\right) t\right] .
$$

Applying in (14) $t=\frac{l}{u}$ with $\eta=1-\frac{C_{i 2}}{C_{i 1}}$ receiving

$$
\eta=1-\exp \left[-\frac{\left(k_{i}+k_{i}^{\prime}\right) l}{u}\right]
$$


From (15) has concluded, about air cleaning efficiency in the wet electro filter of i-st hazardous gaseous component to increase with an oxidation absorption constant k'i-st hazardous gaseous component by ozone and absorption speed constant k'I in current components by liquid, moistening to condensed electrodes, as well with increasing an active length electrodes 1 , but decreasing with rising electrodes between space $h$ and air stream speed $u$.

To determine the effectiveness of environment's cleaning from hydrogen sulphide, experimental stand was developed. This stand includes a prototype of the wet one-zoned electro-filter.

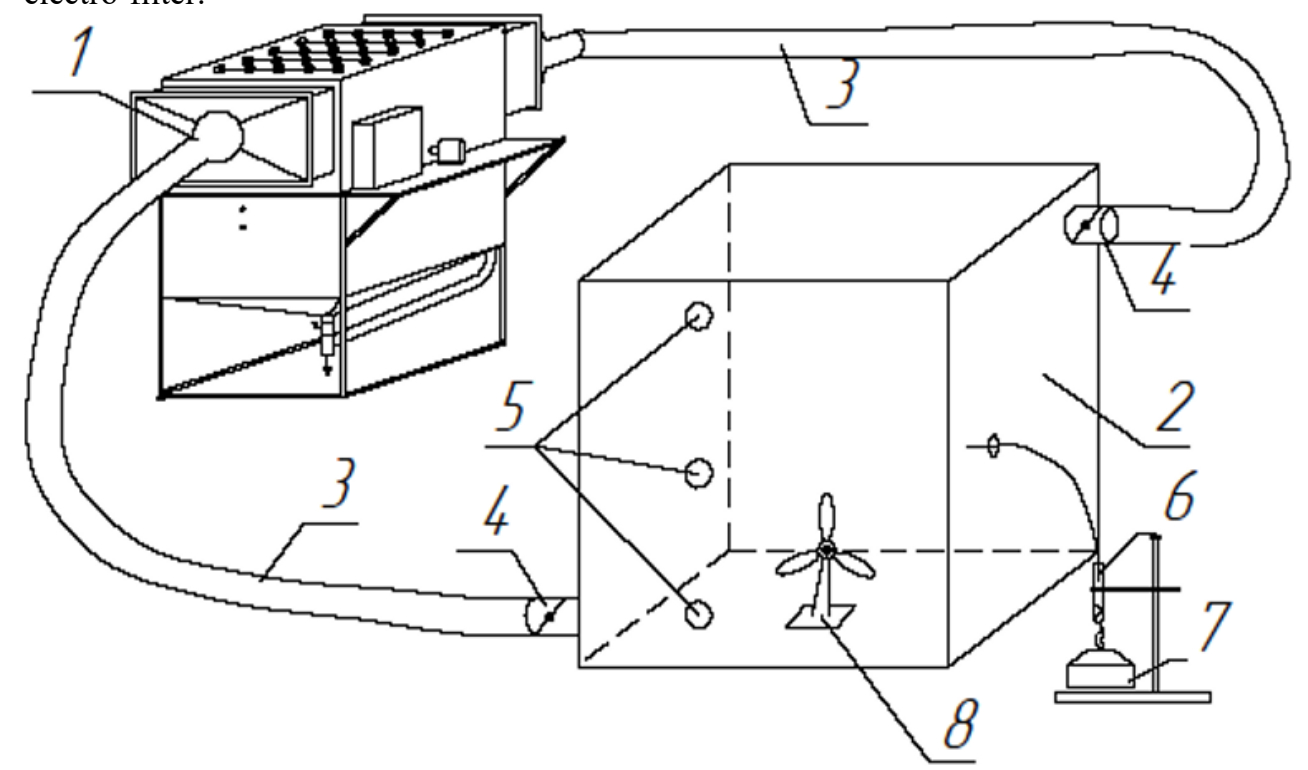

Fig. 4. Functional scheme of experimental stand: 1 - wet electro-filter; 2 - hermetic accumulative reservoir $\mathrm{V}=1 \mathrm{~m}^{3} ; 3$ - corrugated connective air ducts; 4 - valve; 5 - Points of extraction air samples; 6 - vial of reagents; 7 - gas burner; 8 - Fan.

The purpose of the research is to identify air cleaning efficiency from hydrogen sulphide, when a wet electro-filter is working in these four modes.

Mode «0» without cleaning (corona charges system without voltage, moistening liquid is missing)

Mode «C» of the one zoned dry electro-filter (corona charges system under voltage, moistening liquid is missing) full)

Mode «A» of the absorber (corona charges system without voltage, moistening liquid is

Mode «M» of the one zoned wet electro-filter(corona charges system under voltage, moistening liquid is full) each mode, the experiment was carried out according to the procedure below.

The experiment, with a 3-fold repeat, the initial concentration of hydrogen sulfide was measuring in a sealed storage tank and in the surrounding air. Then, hydrogen sulfide was injected into the tank to a concentration of $50 \mathrm{mg} / \mathrm{m} 3$ and air samples were taken at control points using a gas analyzer. Water was poured into the lower part of the WOF intended for the liquid washing the precipitation electrodes (or not filling for modes " 0 " and "C"). If the value of the concentration of hydrogen sulfide differed by levels, the fan was 
turned on, which serves to mix the air in the tank, which was turned off before the recycling fan started.

Furthermore, the recycling fan is turned on and valves are opened. These valves to separates a reservoir from WOF. On the corona charged system WOF to conduct is $15 \mathrm{kV}$ voltage (or not conducts in modes « $\langle »$ and «A»). The time was measured. This time shows how much air has been pumped from WOF. Upon expiry this time the recycling fan is turning off and valves have closed. Furthermore, the fan is turned on. This fan of mixing air pollution in a cube. After that air samples have taken [20].

fixation results of hydrogen sulfide concentration in the environment reservoir, experiment have repeated till hydrogen sulfide is not decreased to $5 \mathrm{mg} / \mathrm{m} 3$. This experiment has been repeated 3 times.

the received average data can be identified of air cleaning efficiency from hydrogen sulfide in a reservoir by the equation [21]:

$$
\eta=\frac{C_{H_{2} S_{B x .}}-C_{H_{2} S_{B b x .}}}{C_{H_{2} S_{B x} .}} \cdot 100 \%
$$

Where, $C_{H_{2} S_{B x} \text {. }}$ concentration of hydrogen sulfide on WOF entrance, $\mathrm{mg} / \mathrm{m}^{3}$

$C_{H_{2} S_{\text {bax. }} \text {. }}$ concentration of hydrogen sulfide on WOF exit, $\mathrm{mg} / \mathrm{m}^{3}$

\section{Results}

According to the data can be build parametric plot $y=f(k)$ for all modes of experimental stand. (Picture 5). Where $\mathrm{k}$ - multiplicity air change in the reservoir.

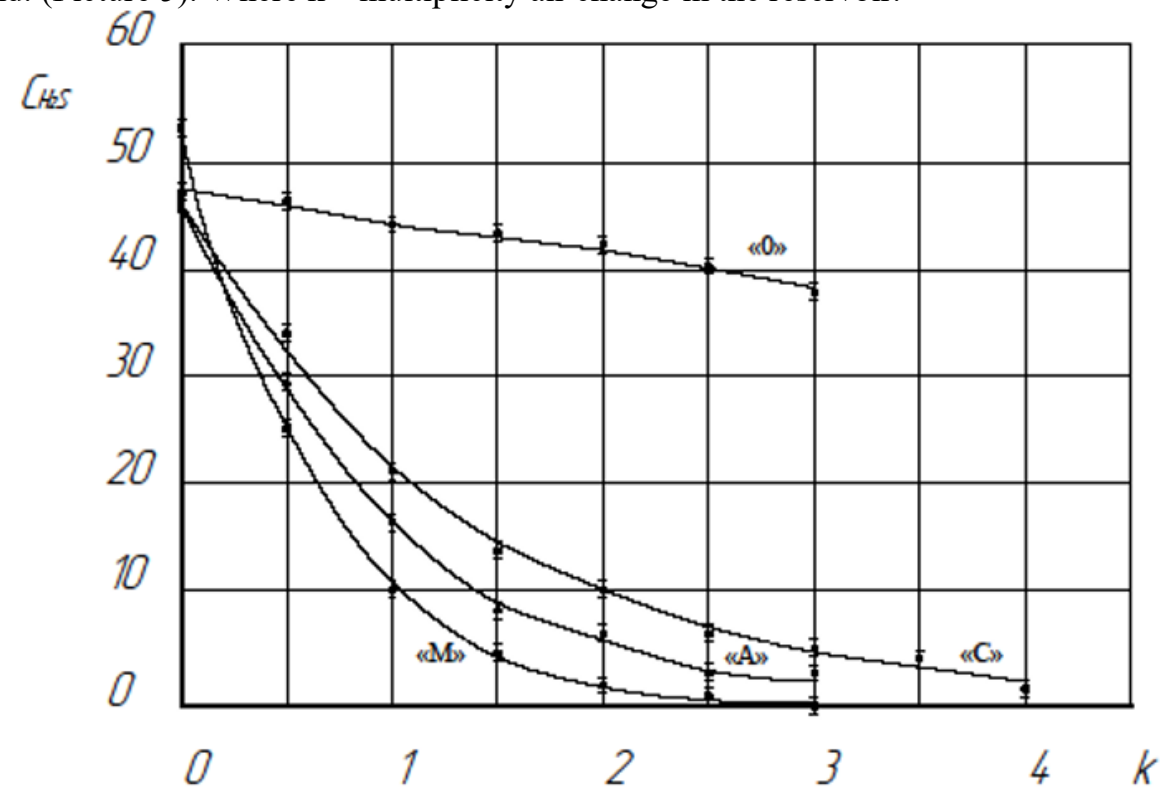

Fig. 5. Dependency of air cleaning efficiency from hydrogen sulphide in modes $« 0 »,\langle C »,\langle A » и$ «M» of air change multiplicity. 
The diagram has shown of decreasing hydrogen sulfide concentration in cleaning air is more intensive in the «M» mode. The efficiency this mode is 80 percent.

\section{Concludes}

1. These electro-filters are perspective and have high efficiency of filter apparats of cleaning and purification of ventilation air in animal premises.

2. The wet electro-filter, thanks to the high capacity of dust and continuous regeneration of condensed electrodes is most suited for cleaning and purification of the air stream in animal premises.

3. Thanks to constructive and technological features the WOT has is high efficiency of air stream cleaning from hydrogen sulfide. This efficiency is 80 percent.

\section{References}

1. A.G., Vozmilov, R.Yu., Ilimbetov, D.V., Astafev, The Usage of Ozone in Agriculture Technological Processes. 2nd Int. Conf. on Ind. Eng., Appl. and Manufact. (ICIEAM) Proseedings (2016)

2. A.G., Vozmilov, M.V., Vlasov, Exhaust air in industrial poultry farming. AIC of Russia, vol. 56, pp. 29-31 (2010)

3. L.N., Andreev, V.V., Yurkin, Energy efficient technologies of microclimate creation in animal husbandry. Proc. of the Int. Conf. "Actual Issues of Mech. Eng." (AIME 2017) doi:10.2991/aime-17.2017.11

4. S.I., Ivanov, G.N., Samarin, Energy efficient microclimate formation. Rural mechanic, vol. 1(47), pp. 28-29, (2013)

5. N.I., Smolin, L.N., Andreev, V.V. Yurkin, Investigation of operational characteristics of two-stage wet electrostatic precipitator in laboratory conditions. Vestnik Krasnoyarsk state agrarian University, vol. 8, pp. 115-122 (2016)

6. G.N., Samarin, A.N., Vasilyev, A.A., Zhukov, S.V., Soloviev, Optimization of microclimate parameters inside livestock buildings. Adv. in Intell. Syst. and Comp., vol. 866, pp. 337-345 (2019)

7. S.V., Os'kin, V.A., Didych, A.G., Vozmilov, Key Ways of Energy Saving in Pump Units for Melioration and Irrigation Systems. Int. Conf. on Ind. Eng., Appl. and Manufact. ICIEAM (2017)

8. R.Yu., Ilimbetov, V.V., Popov, A.G., Vozmilov, Comparative analysis of "NGTU Electro" electric car movement processes modeling in MATLAB Simulink and AVL Cruise software. Int. Conf. on Ind. Eng. Proc. Eng. vol. 129, pp. 879 - 885 (2015)

9. I.M., Dovlatov, L.Yu., Yuferev, Methods of air disinfection from pathogenic microflora in poultry facilities. Current trends in the scientific support of the agroindustrial complex Collective monograph. Edited by V.V. Okorkova. Ivanovo, pp. 305308 (2019)

10. A.A., Dmitriyev, V.P., Frayshteter, Improving energy efficiency of building heating and ventilation systems by use of two-stage electrostatic precipitator. Oil industry, vol. 6, pp. 122-123 (2014)

11. F.Ya., Izakov, V.B., Fayn, $O$ the calculation of a system for cleaning air from dust in ventilated livestock buildings. Trudy ChIMESKh, vol. 81, pp. 130-133 (1974) 
12. A.A., Andreev, A.G., Vozmilov, V.A., Kalmakov, Development of the Experimental Assembly for Studying the System Maintaining Battery Optimal Temperature. Int. Conf, on Ind.1 Eng., Appl. and Manufact. ICIEAM (2017)

13. A.V., Shpilko, V.I., Dragaytsev, N.M., Morozov, P.N., Kabanov, Economic efficiency of mechanization of agricultural production. Moscow, Russ. Acad. of Agric. Scie., p. $346(2001)$

14. A.S., Kizurov, I.P., lapshin, S.N., Kokoshin, Differentiated drying of the mixtures colloidal components used in the construction of underground infrastructure. Proc. Eng. vol. 165, pp. $806-816$ (2016)

15. N.V., Samoylova, Methods of economic assessment of energy in agricultural production target energy industry. Izvestia Timiryazevskaya Agricultural Academy, 6. ,pp. 94-101 (2013)

16. A.G., Vozmilov, V.N., Mishagin, L.N., Andreev, D.V., Astafiev, Wet single-zone electrostatic precipitator. Patent for invention RUS 2343362 (2007)

17. A.G., Vozmilov, V.B., Fain, L.N., Andreev, A.A., Dmitriyev, V.V., Yurkin, Analysis of air purification systems in livestock and poultry farms. Electrotech. and inf.compl. and syst., vol. 4, pp. 45-51 (2014)

18. Entstaubung industrieller Gase mit Elektrofiltern / Harry J. White / Deutscher Ver-lag für Grundstoffindustrie, p. 197 Leipzig (1969)

19. A.N., Vasiliev., D.A., Tarkhov, T.A., Shemyakina, Multilevel models of the urban transport system and its impact on the environment in megacities. Prob. of Inf. in Ed., Man., Econom. and Tech., collection of articles of the XV International Scientific and Technical Conference. Edited by V.I., Gorbachenko, V.V., Drozhdina, pp. 84-87 (2015)

20. S.N., Kokoshin, N.N., Ustinov, B.O., Kirgincev, The use of flexible tubular elements of the overhaul and tunnels reconstruction. Proc. Eng., vol. 165, pp. 817-828 (2016)

21. A.A., Dmitriyev, A.G., Vozmilov, L.N., Andreev, B.V., Zherebtsov, About the main tasks to be solved in the design of wet electrostatic precipitators. Electrotech. and inf. Compl. and syst., vol. 1, pp. 24-28 (2014) 